Journal of Social Science and Humanities, 4 (1): 01-05, 2021

e-ISSN: 2600 - 9056

(C) RMP Publications, 2021

DOI: DOI: 10.26666/rmp.jssh.2021.1.1

\title{
Online Classroom Challenge during the COVID-19 Pandemic
}

\author{
Syaiful Baharee Jaafar, Noor Hanim Ismail and Rosnida Othman \\ Commerce Department. Polytechnic of Tuanku Sultanah Bahiyah \\ Kulim Hi-Tech Park, 09000, Kedah, Malaysia
}

\begin{abstract}
The COVID-19 pandemic, which affects the world, changes how we teach and learn from traditional approaches to technology approaches. The online classroom is a way to transfer the knowledge, and skills of the lecturer to the student. There is an excellent challenge amongst the lecturer to change the face-to-face method in the online classroom. The purpose of this study is to discuss the challenge facing the online in-class lecturer during the COVID-19 pandemic. The challenges for the lecturer are teaching and learning, technology, and workload. This challenge must be managed properly to ensure the effectiveness of the online classroom and students benefit from it.
\end{abstract}

Keywords: Online teaching and learning, Challenge, Pandemic Covid-19

\section{INTRODUCTION}

The COVID-19 pandemic began in Wuhan, China, in November 2019 and expanded rapidly worldwide. The pandemic has affected several sectors, including the aviation industry, tourism, health, the economy, and education. Most countries are using the locked-down approach to halt the spread of COVID-19. The consequences of such an approach have seriously affected the economy, including the education sector. With the school's closure and the institution, thousands of students are seriously affected. The COVID-19 pandemic is a new educational standard, particularly for higher education institutions when face-to-face learning does not allow it.

The COVID-19 pandemic is creating a new phase of education, especially in Malaysia, where digital education is shifting from face-to-face. This scenario is unexpected, especially in higher education institutions where most of the teaching and learning is provided online. This shows that, the teaching method may be the change where is a smart technology become more important as a medium. In contrast, traditional methods such as face-to-face learning are preferred but do not make it possible on campus.

Students are preferred to learn on campus because they can have social activities, a class environment and interaction with lecturer. Online courses are challenging because all factors are less relevant and can have an impact on student motivation. Online classes are more at self-learning, so the student should have a solid incentive to push to continue learning. Furthermore, a great challenge for the lecturer is the lack of knowledge and skills on technology can affect the online classroom.

Teaching and learning materials should be designed and structured so that students can participate in online classes. Therefore, the lecturer had to dedicate more time to developing materials. In addition, the lecturer must make a review be well informed about the subject and to increase his self-confidence during the teaching and learning process.

Almost a lecturer is the lacks knowledge in technology, especially about to software or hardware. Online courses are computer-related and can cause technophobe. This situation puts pressure on the lecturer to move from traditional learning to technology.

The purpose of this study is to discuss the challenges faced by the online classroom lecturer during the COVID-19 pandemic. The challenges facing the speaker are teaching and learning, technology and workload. This challenge must be adequately managed to ensure the efficiency of the online classroom, and students benefit from it. 


\section{LITERATURE REVIEW}

Pandemic COVID-19, spread around the world, is shifting the education system into a new standard that is connected to the online classroom. Thus, technology plays an essential part in transferring of knowledge and skills. Higher education institutions have been affected by the pandemic, and education and the learning process must take place online. Students do not allow enrollment on campus, but study at home. An online classroom is a different approach to the face-toface method, like lectures, materials, questions, and answers, tutorials and workload. In addition to this emotional student and technology wise also affect the online classroom. Lecturers need to have better knowledge to ensure the student can understand the subject, so that the preparation is essential.

This study looked at variables such as teaching and learning, technology, workload, and the emotional challenge in an online classroom. The following chapter is a more in-depth discussion regarding all variables as a challenge to the lecturer.

\section{Teaching and Learning}

Prior to that, teaching and learning related to the physical student on campus, which is face-to-face learning. Face-to-face learning can provide a better relationship between the student and lecturers, so that the student is capable of focusing during the classroom. In addition, the student can answer any question and obtain the comments of lecturer at the same time. This indicates that teaching and learning take place on campus in a way that increases the effectiveness of student understanding. Furthermore, Foti argues that active interaction is an essential precondition for learning and cannot be replaced by distance learning [1].

In addition, the teacher is also capable of identifying with the student's body language either they are understood or vice versa as far as the subject is concerned. However, the online classroom becomes the primary medium of contact during the COVID-19 pandemic as the student does not allow to go to campus, but to study at home. Nevertheless, the lack of communication throughout the online class as well as the lack of synchronous educational activities caused frustration among students as they did not to understand the courses [2].

The most important concerning the online classroom is the learning process should be similar to the one on campus as follows the curriculum counts. A teacher plays a crucial role in student success, both in traditional and distance learning [3]. Learning on campus is an easier process when documents are provided in hard copy, such as a manual, book or module.

The documents are used for review or exercise, and subsequent discussions are more effective. Concerning the information is not clear may explain by the lecturer, and this may be an indication of the student's understanding. According to Chao, Saj, \& Tessier, one of the most significant aspects influencing the quality of distance education is the quantity and quality of learning and teaching resources and materials [4]. Lloyd, Byrne, \& McCoy, too supported this view and revealed that the effectiveness of distance education is closely associated with pedagogical and material support within the process [5]. However, the situation is different from the online classroom as far as materials and understanding are concerned. According to Stone \& Springer, teachers agreed that distance learning requires a different approach and skills in in-person education [6].

Materials must be converted from paper to electronic to be made available online. Additionally, students should access documents before and during the course for review. Materials should be updated and appropriate for the current situation. It is challenging to ensure that the class does not interrupt due to fewer materials. In addition, the design of materials is essential to ensure the student's capacity to read and understand. Suitable materials can lead a better understanding and linkages with better academic performance. Therefore, the materials should be better organized and easily understood.

Stone \& Springer note that strong teacher presence and appropriate course design were the best way to prevent long-distance drop-outs [6]. According to Seaman, low-quality materials can serve as the foundation for opposing views on distance education [7]. Thus, there is a more substantial need for educational organizations to improve their curriculum, and the usage of new instructional methods and strategies should be of utmost significance [8]. This statement also was supported by Adnan \& Anwar which indicated that educational organizations need to improve their curriculum and design appropriate content for online lectures [9].

A better performance is accompanied by better experience of the subject matter. For a better understanding, class participation is complimented as indicating the initial intention to learn. It is difficult for the lecturer to ensure that the student's physical, and spiritual connections are aligned with the topic. The implication of this notion has the potential to improve understanding. However, if the student is physically active in an online course but less focused, the subject 
may become difficult and affect performance. According to Niemi, \& Kousa, teachers were concerned about how they can take place remotely, create an enjoyable learning environment, and make the student feel more important than isolated [10].

Online courses can provide more flexibility for students and it is easily accessible and can even reach into rural and remote areas [11]. This situation may challenge the lecturer to follow up with the students to follow the classes consistently. Moreover, the student motivation can become a problem for continuing to follow online courses. Students are less motivated to answer lecturer questions as they do not communicate physically. This can impact student concentration and lack of understanding of the subject matter. Song, Singleton, Hill \& Koh mentioned in their study that difficulties in understanding instructional goals are one of the significant barriers for online learning saying [12] and it was supported by [11]. According to Ozkara \& Cakir, students tended to have a positive attitude towards distance learning, but found the ability to communicate in person to be more motivated [13].

An online classrooms like the one shared today, and there should be no individual responsibilities to ensure the continuation of education, but more involving the institution itself. Not all lecturers are knowledgeable about the online classroom. Distance education must be based on an ordinary school strategy that everyone is engaged in [10]. Supported by [6] highlighted that teachers also need support, sufficient resources, and time to implement distance learning.

\section{Workload}

The lecturer and the student related to teaching and learning should be aligned with achieving a better result. Understanding topics as a priority may lead the lecturer to work harder. Assignment and notes, build understanding if all tasks have been completed. This scenario can increase the lecturer's workload, but it is needed. When a student does the review and practice exercise by assignment or tutorial possibility to reach a higher grade is higher.

The notes should be prepared in a structure that allows the student to understand. This requires additional preparation time, and at the same time the lecture must continue. The face-to-face learning notes will clear through the lecturers, and easy to understand by the students. However, online class need to be clearly clarified with structured notes. This is an indication that the lecturer needs to do extra work. Student is only interested in getting better results so that they can get a job after graduation. It is essential for students need to understand this topic, especially in online classes. The situation puts pressure on the lecturer to ensure that the online classroom is effective. The lecturer will review the subject to ensure they know before online class start.

Course preparation can increase the level of confidence throughout the teaching and learning process. The implication of this view can enhance the lecture course with a good knowledge of the subject and ability to explain better avenues for a better understanding. This situation requires the lecturer to dedicate time to the review, which adds work. This has the potential to motivate students to enjoy the classroom. Motivation plays an essential role in students' engagement during online class and activities [14].

\section{Technology}

The COVID-19 pandemic is changing traditional practices to technology education and learning. The lecturer should be familiar with the technology to ensure that knowledge and skills can be successful. However, the lecturer has few skills and preparation for teaching online. This scenario can affect the online courses for students depends on the lecturer's capacity for knowledge and competencies. Technophobe among the lecturer can cause more inefficient online courses.

Online lessons depended on technology, so it is a necessary for lecturer to learn how to teach using technology. However, a lack of technology knowledge can contribute to a lecturer's difficulty teaching online. A seminar or lesson should be offered to improve technology competencies to ensure the effectiveness of online courses. Without good computer skills, the whole teaching and learning process will be affected. Trust \& Whalen reported that most teachers interviewed had never taught online before [15].

Shah, \& Shah where most of the teachers have no experience or minimal capability in online teaching [16]. Nevertheless, since the whole world was plagued with this disease, one should prepare and accept this change. Training can be carried out so that teachers and students can adapt to distance education more efficiently, and the necessary infrastructure support can be further strengthened to eliminate technical problems [2]. In addition, Toquero also supported this statement and mentioned that the training is needed to enhance the competencies of the teachers and it will improve students learning [8].

Another challenge with online courses has to do with access and equipment. A student may not access the online courses regarding the coverage issue or low speed. In addition, the teaching and learning process may become less efficient if the student does not have a 
laptop. This scenario can reflect the lecturer related to the transfer of knowledge and skills to the student as the lecturer also technophobe including software and hardware.

Before the COVID-19 outbreak, students prefer face-to-face learning as their mode of study. In addition, the lecturer was also interested in learning on campus that is more effective because of having good communication, classroom environment, and social relations. But, the online class puts stress on the lecturer to learn the technology. Technology readiness that the lecturer does not prefer to teach an online course due to lack of skills. It is a challenge for the institution to ensure that the efficient online classroom will be successful.

Since online courses have become commonplace in education today, the lecturer must prepare to learn technology, especially software or computer equipment. This provides a chance to improve knowledge and skills to confirm whether online courses tend to be successful. Without a clear explanation and the priority of learning new knowledge with respect to online courses can influence the preparation of the lecturer.

The lecturer should explain a new standard of education where the student does not permit on campus so that teaching and learning have to be done online. Therefore, the lecturer should learn the technology and must learn from the beginning the technologies and online software available to have better preparation [17]. Furthermore, the institution should be responsible for the provision of training and resources to the lecturer on technology-based learning to enhance knowledge and skills. The institution will also receive an extended long lasting benefits, from this process [18].

Lack of preparedness and understanding of technology associated with mental stress among the lecturer. This does not do any good for the teaching and learning process since distracting emotional lecturer. Teaching and learning should be fun and enjoyable and can attract interest from students. However, if the lecturer is working under pressure, it can affect the class and the student. In other words, online classroom success is not strictly dependent on physical lecturer but also emotional. There has never been done before, but it is becoming common practice during COVID-19.

\section{CONCLUSION}

The COVID-19 pandemic, which has spread rapidly around the world, including in Malaysia, can lead to a new phase of education, primarily in-person in online classrooms. The teaching sectors affected, such as primary school, secondary school, and higher education institutions, where education and learning do not occur on campus, but are replaced with the online classrooms. It is challenging for lecturers in higher institutions with new norms in the online classroom.

Lecturers face challenges such as teaching and learning, technology workload and emotions, particularly during the COVID-19 pandemic, when campus studies do not allow this, but instead of the online classroom. The lecturer must do the preparation such as the revision, make a note of the hard copy turn to the electronic copy. More time is required to prepare for effective instruction and learning. If the student lacks an understanding of the subject, it is challenging to complete the exam. At worst, the student can fail the subject.

Most of the lecturer's phobia of technology, such as computer equipment and software. They must spend more time learning the computer to ensure that the online classroom process is effective. The lecturer needs to know how the online classroom works because if it up, they know how to set up. This scenario challenge when the lecturer needs to continue learning about how to do it in an online classroom.

Additionally, lack of preparation may contribute to stress that is lead to depression. It can affect the student in general when the online classroom is less effective. It is essential to ensure the emotional lecturer is stable and able to provide knowledge smoothly. Also, the class should be enjoyed and easy for students to understand.

\section{REFERENCES}

[1] Foti, P. 2020. Research in distance learning in Greek kindergarten schools during the pandemic of COVID-19: Possibilities, dilemmas, limitations. European Journal of Open Education and Elearning Studies, 5 (1), 19-40. http://dx.doi.org/10.46827/ejoe.v5i1.3080

[2] Hebebci, M. T., Bertiz, Y., \& Alan, S. 2020. Investigation of views of students and teachers on distance education practices during the Coronavirus (COVID-19) Pandemic. International Journal of Technology in Education and Science (IJTES), 4(4), 267-282.

[3] Rice, K. 2006. A Comprehensive look at distance education in the K-12 context. Journal of Research and Technology in Education, 38 (4), 425-448. https://doi.org/10.1080/15391523.2006.10782468 
[4] Chao, T., Saj, T., \& Tessier, F. 2006. Establishing a quality review for online courses. Educause Quarterly, 29(3), 32.

[5] Lloyd, S. A., Byrne, M. M., \& McCoy, T. S. 2012. Faculty-perceived barriers of online education. Journal of online learning and teaching, 8(1).

[6] Stone, C. \& Springer, M. 2019. Interactivity, connectedness and "teacher-presence": Engaging and retaining students online. Australian Journal of Adult Learning, 59 (2), 146-169.

[7] Seaman, J. 2009. Online Learning as a Strategic Asset. Volume II: The Paradox of Faculty Voices-Views and Experiences with Online Learning. Results of a National Faculty Survey, Part of the Online Education Benchmarking Study Conducted by the APLU-Sloan National Commission on Online Learning. Association of Public and Land-Grant Universities.

[8] Toquero, C. M. 2020. Challenges and Opportunities for Higher Education Amid the COVID-19 Pandemic: The Philippine Context. Pedagogical Research, 5(4).

[9] Adnan, M., \& Anwar, K. 2020. Online Learning amid the COVID-19 Pandemic: Students' Perspectives. Online Submission, 2(1), 45-51.

[10] Niemi, H. M., \& Kousa, P. 2020. A case study of students' and teachers' perceptions in a Finnish high school during the COVID pandemic. International Journal of Technology in Education and Science (IJTES), 4 (4), 352-369.

[11] Dhawan, S. 2020. Online learning: A panacea in the time of COVID-19 crisis. Journal of Educational Technology Systems, 49(1), 5-22.

[12] Song, L., Singleton, E. S., Hill, J. R., \& Koh, M. H. 2004. Improving online learning: Student perceptions of useful and challenging characteristics. The internet and higher education, 7(1), 59-70.

[13] Ozkara, B \& Cakir, H. 2018. Participation in online courses from the students' perspective. Interactive Learning Environments, 26 (7), 924942.https://doi.org/10.1080/10494820.2017.1421 562

[14] Pond, J. W., \& Chini, J. J. 2017. Exploring student learning profiles in algebra-based studio physics: A person-centered approach. Physical Review Physics Education Research, 13(1), 010119.
[15] Trust, T., \& Whalen, J. 2020. Should teachers be trained in emergency remote teaching? Lessons learned from the COVID-19 pandemic. Journal of Technology and Teacher Education, 28 (2), 189199.

[16] Subedi, S., Nayaju, S., Subedi, S., Shah, S. K., \& Shah, J. M. 2020. Impact of E-learning during COVID-19 pandemic among nursing students and teachers of Nepal. International Journal of Science \& Healthcare Research, 5(3), 68-76.

[17] Nuere, S., \& de Miguel, L. 2020. The digital/technological connection with Covid-19: An unprecedented challenge in university teaching. Technology, Knowledge and Learning, $1-13$.

[18] Daniel, J. 2020. Education and the COVID-19 pandemic. Prospects, 49(1), 91-96. 